To the Editors:

\title{
Platelet recovery in dengue - a reply
}

\section{S Yasri ${ }^{1}$, V Wiwanitkit ${ }^{2}$}

Ceylon Medical Journal 2014; 59: 109

The article on platelet recovery in dengue is interesting [1]. Gooneratne et al. concluded that "the platelet recovery rates of patients from the 2011 outbreak were found to be slower than the platelet recovery rates of patients from the 2010 outbreak" [1]. This finding is interesting and requires further assessment. The difference might be due to several factors such as underlying haematological condition of the patients, age group, severity of dengue infection, strain of virus and it can also be an accidental finding.

For example, it is obviously noted that "platelet recovery was significantly slower with increasing grade" among the patients with bleeding presentation [2]. The cases with dengue shock syndrome usually have longer recovery periods [3]. Also, if the patient has underlying white blood cell malignant problem, the recovery time will be significantly delayed [4].

\section{References}

1. Gooneratne L, Wimalachandra M, Wijerathna J, Karunathunga $\mathrm{N}$, Jayasinghe S. Slow platelet recovery pattern during the 2011 dengue outbreak: a preliminary report. Ceylon Medical Journal 2014; 59: 61-3.

2. Ahmad S, Dhar M, Srivastava S, Bhat NK, Shirazi N, Biswas D, Kadian M, Ghai S. Dengue hepatitis sans dysfunction: experience of a single tertiary referral centre in the north Indian state of Uttarakhand. Tropical Doctor 2013; 43: 62-5.

3. Joshi R, Baid V. Profile of dengue patients admitted to a tertiary care hospital in Mumbai. Turkish Journal Pediatrics 2011; 53: 626-31.

4. Ramzan M, Yadav SP, Dinand V, Sachdeva A. Dengue fever causing febrile neutropenia in children with acute lymphoblastic leukemia: an unknown entity. Hematology, Oncology and Stem Cell Therapy 2013; 6: 65-7.

${ }^{1}$ Primary Care Unit, KMT Center, Bangkok Thailand and ${ }^{2}$ Hainan Medical University, China.

Correspondence: SY, e-mail: <sorayasri@outlook.co.th>. Competing interests: none declared. 